\title{
Desempenho agronômico e divergência genética de genótipos de coentro ${ }^{1}$
}

\author{
Agronomic performance and genetic divergence of coriander genotypes
}

\author{
Cândida Hermínia de Magalhães Bertini²*, Everton Alves Rodrigues Pinheiro ${ }^{3}$, Gabriel Nuto Nóbrega ${ }^{3}$ e José $^{2}$ \\ Moacir de Lima Duarte ${ }^{3}$
}

\begin{abstract}
Resumo - Cinco genótipos de Coriandrum sativum, procedentes de diferentes regiões do Estado do Ceará e duas cultivares comerciais, foram avaliados objetivando-se identificar genótipos com potencial agronômico para serem utilizados em programa de melhoramento genético por meio de análise de desempenho e divergência genética. $\mathrm{O}$ trabalho foi conduzido no período de setembro a dezembro de 2007 no município de Fortaleza-CE. O delineamento utilizado foi o aleatorizado em blocos com três repetições, onde os genótipos e cultivares foram considerados tratamentos. Na análise de desempenho verificou-se diferença entre as médias dos genótipos avaliados para as características: altura da planta, diâmetro do colo, surgimento da primeira inflorescência, antese, média de umbeletes/umbela, início e término do amadurecimento dos frutos. Entretanto, para as características agronômicas, número de folhas aproveitáveis e peso de cem frutos, não se verificou diferença entre as médias dos genótipos avaliados em relação às cultivares comerciais. Quanto à divergência, o genótipo 1 , proveniente da região litorânea de Caucaia, foi o mais divergente, podendo ser usado em cruzamentos com os demais genótipos para a obtenção de populações segregantes. Os genótipos mais similares foram o Verdão-SF177 e o genótipo proveniente de Juazeiro. Os resultados do agrupamento não mostraram relação com as diferentes localizações geográficas dos genótipos avaliados.
\end{abstract}

Palavras-chave - Coriandrum sativum. Fenologia vegetal. Melhoramento genético. Diversidade genética.

\begin{abstract}
Five genotypes of coriander (Coriandrum sativum) from different regions of Ceara-Brazil and two cultivars were assessed with the objective to identify genotypes with agronomic potential for use in breeding program using performance analysis and genetic divergence. The study was conducted during the period of September to December, 2007 in Fortaleza - Ceará. It was used a randomized blocks design with three replicates where the genotypes and cultivars were considered treatments. In the performance analysis, difference was observed among the averages of genotypes evaluated for the following characteristics: height of the plant, diameter, emergence of the first inflorescence, anthesis, mean umbellate/ umbel, beginning and end of the ripening fruit. The treatments from Caucaia and Juazeiro were the most regular regarding precocity. However, considering agronomic characteristics, number of usable leaves and weight of a hundred fruit, there was no difference between the averages of the evaluated genotypes in relation to commercial cultivars. With the divergence analysis, the genotype 1, from the coastal region of Caucaia was the most divergent and can be used at crossings with other genotypes for obtaining segregating populations. The genotypes that had lower genetic distance were Verdão SF177 and genotype from Juazeiro (semi-arid zone). The results of the group showed no relationship to the different geographical locations of genotypes evaluated.
\end{abstract}

Key words - Coriandrum sativum. Plant phenology. Genetic diversity. Plant breeding.

\footnotetext{
*Autor para correspondência

${ }^{1}$ Recebido para publicação em 31/10/2009; aprovado em 04/06/2010

Pesquisa de Iniciação Científica desenvolvida por alunos do PET, CCA/UFC

${ }^{2}$ Departamento de Fitotecnia, Centro de Ciências Agrárias, Universidade Federal do Ceará, Fortaleza-CE, Brasil, candida_bertini@yahoo.com.br

${ }^{3}$ Graduando em Agronomia, Departamento de Fitotecnia, Universidade Federal do Ceará, Fortaleza-Ce, Brasil, evertonvest@yahoo.com.br,

nutonobrega@hotmail.com, moacir.ufc@oi.com.br
} 


\section{Introdução}

O coentro (Coriandrum sativum L.) pertencente à família das Apiaceae é uma hortaliça-condimento de ciclo anual, sendo uma espécie de polinização cruzada, realizada principalmente por insetos (WANDERLEY; NASCIMENTO, 2008).

No Brasil, o coentro é amplamente consumido como condimento. É provável que, em valor de mercado, seja a segunda hortaliça folhosa em importância para o Brasil, perdendo somente para a alface. Em geral, é cultivado durante todo o ano e por um grande número de produtores, exercendo um papel social muito importante, principalmente nas regiões Norte e Nordeste do Brasil (BEZERRA et al., 1990; WANDERLEY; NASCIMENTO, 2008) onde seu cultivo é realizado predominantemente nas zonas periféricas das cidades (hortas comunitárias), exclusivamente para a produção de massa verde (BARROS JÚNIOR et al., 2004).

Os produtores dessa olerícola visam à produção de folhas e frutos, onde as folhas servem como condimento em sopas e outros alimentos e os frutos podem ser utilizados em pastelarias e confeitarias, além de fazer parte da composição de bebidas alcoólicas. Alguns tipos varietais são utilizados para extração de óleos essenciais de alto valor agregado, empregados nas indústrias de flavorizantes, cosméticos e medicamentos (RANGAHAU, 2001).

Dentre as principais olerícolas com potencial para produção de sementes na região Nordeste está o coentro. No estado do Ceará, existem produtores de coentro que compram sementes de cultivares disponíveis no mercado e produtores que produzem sua própria semente, ou seja, reservam sempre uma área de plantio para este fim. Assim, eles vão praticando de forma intuitiva uma seleção continuada a cada plantio. Apesar da existência no mercado brasileiro de cultivares de coentro de boa aceitação comercial, não há um programa regional de avaliação de genótipos visando identificar e recomendar aqueles de melhor adaptação às diversas condições agroecológicas das zonas de cultivo (OLIVEIRA et al., 2007). Soma-se a isso escassez de trabalhos de melhoramento genético com a espécie e a utilização de cultivares provenientes de outras regiões, como a região Sul, não levando em consideração as diferenças de comportamento entre as duas regiões (Sul e Nordeste).

No Brasil, pouca pesquisa tem sido feita com coentro, incluindo a tecnologia adequada para a produção (FILGUEIRA, 2000)edesenvolvimentodenovos cultivares (PEREIRA et al., 2005). A condução de experimentos regionais visando estudar o comportamento de novos materiais, incluindo aqueles produzidos pelos próprios agricultores, pode ser uma alternativa para a identificação de genótipos promissores e adaptados às condições locais de cultivo. Uma vez identificados, esses genótipos podem ser usados nos programas de melhoramento da região.

A quantificação da dissimilaridade genética pode ser utilizada pelos melhoristas como um parâmetro na obtenção de segregantes transgressivos (BENIN et al., 2003). Nesse sentido, os métodos multivariados têm oferecido contribuições efetivas na identificação de genótipos para serem utilizados em programas de melhoramento genético de várias culturas (SANTOS et al., 2000), dentre elas, algumas leguminosas, como feijão-caupi (BERTINI et al., 2009) e também hortaliças (BARBIERE et al., 2005, SUDRÉ et al., 2005).

Objetivou-se com esse trabalho avaliar o desempenho agronômico e a divergência genética entre genótipos produzidos por produtores de coentro do estado do Ceará e cultivares comerciais, visando identificar genótipos com potencial agronômico para ser utilizado em programas de melhoramento genético do coentro.

\section{Material e métodos}

O experimento foi conduzido de setembro a dezembro de 2007, no Setor de Horticultura da Universidade Federal

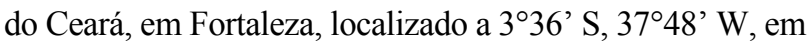
altitude de 19,53 m, clima do tipo Aw' segundo Köppen, tropical chuvoso. A temperatura média $27,4^{\circ} \mathrm{C}$, precipitação pluviométrica $106,7 \mathrm{~mm}$ e a umidade relativa $69,5 \%$ referemse aos meses do desenvolvimento do trabalho.

O experimento foi conduzido em canteiros de $10 \mathrm{~m}^{2}(10 \mathrm{~m} \times 1,0 \mathrm{~m})$ sob o delineamento aleatorizado em blocos, consistindo cada canteiro de um bloco. Foram avaliados sete tratamentos com três repetições. Os tratamentos consistiram de genótipos adquiridos diretamente de produtores de coentro do estado do Ceará, sendo dois desses genótipos provenientes do cinturão verde de Fortaleza (T3-Lagoa Redonda e T4-Sabiaguaba), um do Município de Caucaia (T1) e um do Município de Paracuru (T2), locais pertencentes à região litorânea do Estado. Outro genótipo foi adquirido no Município de Juazeiro (T7) (Zona Semiárida). Além desses genótipos foram utilizados como testemunhas os cultivares Verdão (T5), produzido pela Hortivale-PE e Verdão SF177 (T6), produzido pela Feltrin-RS.

Durante o preparo dos canteiros foram adicionados ao solo 120 litros de composto orgânico e realizada uma adubação química contendo $78 \mathrm{~g} \mathrm{~m}^{-2} \mathrm{de}$ Super Fosfato Simples (140 kg ha $\left.{ }^{-1} \mathrm{de}_{2} \mathrm{O}_{5}\right), 11,7 \mathrm{~g} \mathrm{~m}^{-2}$ de $\mathrm{KCl}\left(70 \mathrm{~kg} \mathrm{ha}^{-1} \mathrm{~K}_{2} \mathrm{O}\right)$ e $9,1 \mathrm{~g} \mathrm{~m}^{-2}$ de Uréia $\left(40 \mathrm{~kg} \mathrm{ha}^{-1}\right.$ de $\left.\mathrm{N}\right)$ com distribuição a lanço. Aos 25 dias, após a emergência, foi realizada uma adubação de cobertura contendo $4 \mathrm{~g} \mathrm{~m}^{-2}$ de N e $7 \mathrm{~g} \mathrm{~m}^{-2}$ de $\mathrm{K}_{2} \mathrm{O}$. 
O plantio foi realizado dois dias após a primeira adubação por meio da abertura de sulcos, espaçados vinte centímetros e profundidade aproximada de quatro centímetros, com uma média de trezentas sementes por sulco. Com vinte dias após a emergência, foi realizado um pré-desbaste e, dez dias depois, o desbaste definitivo permanecendo um total de 25 plantas por repetição sendo avaliadas apenas as seis plantas centrais de cada repetição. Durante a condução do experimento foram realizadas capinas manual e irrigação com sistema de micro-aspersão.

As visitas ao campo foram realizadas diariamente a fim de avaliar as características fenológicas e agronômicas das plantas. Aos 35 dias após a emergência, foi quantificado o número de folhas aproveitáveis por planta (NFA). A partir dessa data, as observações se voltaram para a verificação da mudança do sistema foliar (MSF). Em seguida foi registrado o surgimento da primeira inflorescência, umbela principal (SPI). Posteriormente, foram coletados os dados referentes às demais características avaliadas: início da antese (IA); altura da planta após SPI (A); diâmetro do colo do caule (D); número de umbeletes por umbelas (UMB); início do amadurecimento dos frutos (IAF); término do amadurecimento dos frutos (TAF) e peso de 100 frutos por planta (PCF).

Para análise de desempenho os resultados observados foram submetidos a uma análise exploratória dos dados com o objetivo de se avaliar a homogeneidade de variância e a distribuição normal destes. Como os resultados dos testes de homogeneidade e normalidade foram não significativos, não foi necessário transformar os dados, procedendo-se, em seguida, à análise de variância (ANAVA). Na comparação das médias foi empregado o teste de Scott-Knott com 0,05 de probabilidade. A análise de variância e comparação de médias foi realizada utilizando-se o programa Sisvar (Universidade Federal de Lavras versão 5.0).

$\mathrm{Na}$ análise da divergência genética entre os genótipos, avaliados com relação às dez características citadas anteriormente, foram empregados métodos multivariados. A distância generalizada de Mahalanobis foi utilizada como medida de dissimilaridade entre os genótipos e o método do vizinho mais próximo (VMP), método hierárquico aglomerativo, foi utilizado como método de agrupamento. No método do VMP identificamse, na matriz de dissimilaridade, genótipos mais similares, os quais são reunidos, formando-se um grupo inicial. Posteriormente, o processo de identificação de novos grupos mais similares é repetido até que todos os genótipos sejam reunidos em um único grupo.

Também foi utilizado como método multivariado, o método dos componentes principais. Esse método consiste em transformar um conjunto original de variáveis em outro conjunto de dimensão equivalente, ambos independentes entre si, e retendo o máximo de informação em ordem de estimação (SANTOS et al., 1995). A vantagem da utilização dos componentes principais é que é possível identificar aquelas características de menor importância para explicar a variabilidade genética dos genótipos estudados. Em estudos com caracteres padronizados, nos quais os autovalores são obtidos a partir da matriz de correlação, tem sido comum descartar o caráter de maior coeficiente (em valor absoluto) a partir do último componente até aquele cujo autovalor não exceda 0,70, segundo recomendações de Jolliffe (1972, 1973) e Mardia et al. (1979).

Todas as análises de divergência genética foram realizadas utilizando-se o programa computacional GENES (CRUZ, 2001).

\section{Resultados e discussão}

Quanto ao desempenho agronômico, houve diferença entre as médias dos genótipos avaliados para as seguintes características: altura da planta, diâmetro do colo, surgimento da primeira inflorescência, antese, número de umbeletes/umbela, início e término do amadurecimento dos frutos (TAB. 1). A diferença observada entre as médias de altura dividiu os tratamentos em dois grupos, o primeiro com os genótipos T1 e T4 e o segundo grupo com os demais genótipos, no qual o primeiro grupo obteve a maior média. $\mathrm{Na}$ avaliação do diâmetro, os genótipos T1, T5, T6 e T7 não diferiram entre si e obtiveram valores superiores aos demais. Essas características têm importância nessa cultura no que diz respeito à susceptibilidade ao acamamento, fenômeno indesejável para a produção de frutos. Quanto maior a altura e menor o diâmetro, mais susceptível ao acamamento será a planta.

Para os produtores que objetivam produção de massa verde, a busca de genótipos que apresentem maior quantidade de folhas aproveitáveis (NFA) e que não sejam precoces quanto à floração, são características consideradas importantes. Genótipos mais precoces podem reduzir o número de folhas em detrimento da formação dos pendões florais além de perda no valor comercial devido sua menor palatabilidade. Na avaliação de NFA para os genótipos em questão, não houve diferença entre as médias. Também não foram observadas diferenças entre as médias para o peso de 100 frutos viáveis. Portanto, em relação às características de produção, os genótipos avaliados apresentaram bom desempenho quando comparados com os cultivares comerciais.

Em estudos similares com a cultura do coentro, Oliveira et al. (2007) compararam o Peso da Massa 
Tabela 1 - Altura das plantas (A), diâmetro do colo do caule (D), mudança no sistema foliar (MSF), surgimento da primeira inflorescência (SPI), dias para o início da antese (IA), dias para o início do amadurecimento dos frutos (IAF), dias para o término do amadurecimento dos frutos (TAF), média do número de umbeletes por umbela (UMB), peso de 100 frutos (PCF) e número de folhas aproveitáveis (NFA), em cinco genótipos e dois cultivares de coentro obtidos no estado do Ceará

\begin{tabular}{lrrrrrrrrc}
\hline Características Avaliadas & \multicolumn{1}{c}{ T1* } & \multicolumn{1}{c}{ T2 } & \multicolumn{1}{c}{ T3 } & \multicolumn{1}{c}{ T4 } & \multicolumn{1}{c}{ T5 } & \multicolumn{1}{c}{ T6 } & \multicolumn{1}{c}{ T7 } & CV (\%) & $\mathrm{F}$ \\
\hline A (cm) & $56,56 \mathrm{~b}$ & $49,93 \mathrm{a}$ & $44,87 \mathrm{a}$ & $53,31 \mathrm{~b}$ & $49,55 \mathrm{a}$ & $50,50 \mathrm{a}$ & $48,25 \mathrm{a}$ & 12,65 & $5,69^{*}$ \\
D (cm) & $0,44 \mathrm{~b}$ & $0,39 \mathrm{a}$ & $0,36 \mathrm{a}$ & $0,38 \mathrm{a}$ & $0,42 \mathrm{~b}$ & $0,44 \mathrm{~b}$ & $0,42 \mathrm{~b}$ & 19,51 & $2,58^{*}$ \\
MSF (dias) & $44,60 \mathrm{a}$ & $45,40 \mathrm{a}$ & $47,20 \mathrm{a}$ & $44,80 \mathrm{a}$ & $45,90 \mathrm{a}$ & $45,50 \mathrm{a}$ & $43,30 \mathrm{a}$ & 6,36 & $2,5^{\text {NS }}$ \\
SPI (dias) & $48,20 \mathrm{a}$ & $50,80 \mathrm{~b}$ & $51,70 \mathrm{~b}$ & $51,10 \mathrm{~b}$ & $50,70 \mathrm{~b}$ & $52,50 \mathrm{~b}$ & $47,50 \mathrm{a}$ & 7,45 & $3,54^{*}$ \\
IA (dias) & $53,10 \mathrm{a}$ & $54,90 \mathrm{a}$ & $55,10 \mathrm{a}$ & $55,80 \mathrm{a}$ & $53,90 \mathrm{a}$ & $56,00 \mathrm{a}$ & $49,90 \mathrm{a}$ & 7,88 & $3,65^{*}$ \\
IAF (dias) & $62,60 \mathrm{a}$ & $64,30 \mathrm{~b}$ & $64,90 \mathrm{~b}$ & $62,20 \mathrm{a}$ & $64,70 \mathrm{~b}$ & $64,80 \mathrm{~b}$ & $60,60 \mathrm{a}$ & 6,79 & $2,38^{*}$ \\
TAF (dias) & $78,60 \mathrm{a}$ & $77,70 \mathrm{a}$ & $80,80 \mathrm{~b}$ & $78,30 \mathrm{a}$ & $80,20 \mathrm{~b}$ & $80,70 \mathrm{~b}$ & $77,30 \mathrm{a}$ & 5,33 & $1,77^{*}$ \\
UMB & $4,20 \mathrm{~b}$ & $3,50 \mathrm{a}$ & $4,02 \mathrm{~b}$ & $4,19 \mathrm{~b}$ & $4,01 \mathrm{a}$ & $4,15 \mathrm{~b}$ & $4,33 \mathrm{~b}$ & 14,14 & $2,64^{*}$ \\
PCF (g) & $0,72 \mathrm{a}$ & $0,79 \mathrm{a}$ & $0,82 \mathrm{a}$ & $0,80 \mathrm{a}$ & $0,77 \mathrm{a}$ & $0,78 \mathrm{a}$ & $0,72 \mathrm{a}$ & 21,06 & $0,8^{\mathrm{NS}}$ \\
NFA & $8,60 \mathrm{a}$ & $7,60 \mathrm{a}$ & $7,53 \mathrm{a}$ & $8,53 \mathrm{a}$ & $7,66 \mathrm{a}$ & $7,73 \mathrm{a}$ & $8,40 \mathrm{a}$ & 18,08 & $1,6^{\text {NS }}$ \\
\hline
\end{tabular}

*Médias seguidas da mesma letra, na linha, não diferem entre si pelo teste de Scott-Knott a 0,05 de probabilidade. As siglas T1, T2, T3, T4, T5, T6 e T7 referem-se aos genótipos procedentes de Caucaia, Paracuru, Lagoa Redonda, Sabiaguaba, Verdão, Verdão SF177 e Juazeiro do Norte, respectivamente

Verde (PMV) do cultivar Verdão com linhagens HTV do município de Areia verificando que a cultivar Verdão foi superior às linhagens, com produção de PMV de $5 \mathrm{~kg} \mathrm{~m}^{-2}$. Média esta superior ao alcançado por Marques e Lorencetti (1999), nas condições de Passo Fundo (RS), onde os mesmos verificaram superioridade do cultivar Verdão na produção de massa verde em relação a outros genótipos avaliados, porém com rendimento muito baixo $\left(2,4 \mathrm{~kg} \mathrm{~m}^{-2}\right)$. Lima et al. (2007) avaliando o desempenho agroeconômico dos cultivares de coentro, Verdão e Tabocas, em função de espaçamentos e épocas de plantio, observaram que em relação a produção de massa verde, o cultivar Verdão se mostrou adaptado às condições de cultivo da região semiárida.

Outro fator de extrema importância para os produtores é o conhecimento da duração do ciclo da cultura, uma vez que quanto maior, maior será o tempo da cultura no campo, diminuindo o número de cultivos por ano e aumentando o tempo de exposição ao ataque de pragas. Avaliando os dados obtidos que caracterizam o ciclo da cultura, MSF; SPI; Antese; IAF e TAF, chegou-se a conclusão que, apesar da mudança do sistema foliar não diferir entre os genótipos, houve variação para os demais aspectos. Os genótipos T1 e T7 mostraram-se os mais precoces quanto ao SPI, esse fato se repetiu também para IAF e TAF. Na antese, somente o genótipo T7 diferiu dos demais por sua precocidade. O genótipo T4 também apresentou precocidade no IAF e TAF igualando-se aos genótipos T1 e T7.
No final do ciclo, foi observado que os genótipos T1, T2, T4 e T7 não difeririam entre si, com uma média de 78 dias para o término do ciclo. Na relação umbeletes/ umbela, os genótipos T2 e T5 apresentaram as menores médias quando comparadas com as demais.

Os genótipos T1, T2, e T7 obtidos pelos produtores do estado do Ceará quando comparados com os genótipos comerciais $\mathrm{T} 5$ e $\mathrm{T} 6$, apresentaram um desempenho igual ou superior nas características avaliadas. Os genótipos comerciais, T5 e T6, apresentaram um ciclo fenológico de duração superior em relação a alguns genótipos locais como T1, T2, T4 e T7. O genótipo sete, obtido em Juazeiro, apesar de ser proveniente da zona semiárida, quando avaliado nas condições de Fortaleza, não apresentou muitas diferenças com os demais genótipos obtidos na região litorânea quanto às características avaliadas (TAB. 1).

Os genótipos não diferiram quanto à característica NFA, portanto, para os produtores situados em ambientes semelhantes ao do estudo que buscam a produção de massa verde, qualquer um dos genótipos poderia ser indicado. Porém, para aqueles que visam à produção de "frutos-sementes" a altura e diâmetro são características agronômicas que limitam a escolha dos genótipos a serem cultivados. Já SPI, IAF e TAF são variáveis importantes na determinação da duração do ciclo fenológico. Portanto, os genótipos T1 e T7 mostraram-se como os mais adequados, podendo ser considerados como alternativas para os produtores de coentro do estado do Ceará e bons materiais para serem utilizados em programas de melhoramento. 
No entanto, é importante destacar que a expressão destas características pode variar com o ambiente ou até mesmo em diferentes anos agrícolas, visto que, o estudo não avaliou esta possível variação.

$\mathrm{Na}$ avaliação da divergência genética, de acordo com os valores de dissimilaridade obtidos, a maior distância genética ocorreu entre os pares de genótipos T1 e T3 e a menor distância entre os pares T5 e T6 (TAB. 2). Resultado semelhante foi verificado com o agrupamento realizado com base no método do vizinho mais próximo (VPM) (FIG. 1). A correlação cofenética entre os dados de dissimilaridade e a matriz fenética para os sete genótipos foi igual a 0,85 para o método do VMP, sendo esse valor significativo a 0,01 de probabilidade com base em 1.000 simulações. O genótipo T1 formou um grupo isolado dos demais, apesar deste genótipo ser proveniente da mesma região (litorânea) que a maioria dos genótipos agrupados no segundo grupo. O outro grupo formado foi constituído pelos outros genótipos (T2, T3, T4 e T7) juntamente com os genótipos comerciais (T5 e T6).
A maior distância do genótipo T1, em relação aos demais indica que este genótipo é o mais divergente, podendo ser utilizado em cruzamentos com os outros genótipos para a obtenção de populações segregantes e identificação de genótipos transgressivos, porém, tais afirmativas são válidas para o ano agrícola e o ambiente do estudo, pois, sabe-se que a interação entre genótipo e ambiente pode expressar um novo fenótipo, mudando assim os resultados de agrupamento. Foi verificado, por outro lado, que o genótipo T7 (obtido da região semiárida) foi agrupado juntamente com genótipos obtidos da região litorânea, mostrando que a proximidade entre os genótipos independe da região geográfica. As menores distâncias genéticas obtidas para o genótipo T5 foram com o genótipo T6 e o genótipo T7. O cultivar Verdão foi selecionado pela empresa Hortivale dentro de populações locais do Piauí, Ceará e Pernambuco (COSTA et al., 2008), justificando sua proximidade com genótipos produzidos no Ceará. Segundo Lima et al. (2007), o cultivar Verdão apresenta características adaptadas à região semiárida, afirmativa que corrobora com os resultados de agrupamento obtidos no presente trabalho.

Tabela 2 - Matriz de dissimilaridade dos 21 pares de genótipos* de coentro, obtida por meio dos dados de médias e matriz de variâncias e covariâncias residuais

\begin{tabular}{|c|c|c|c|c|c|c|c|}
\hline & $\mathrm{T} 1$ & $\mathrm{~T} 2$ & $\mathrm{~T} 3$ & $\mathrm{~T} 4$ & $\mathrm{~T} 5$ & T6 & $\mathrm{T} 7$ \\
\hline $\mathrm{T} 1$ & 0,0 & & & & & & \\
\hline $\mathrm{T} 2$ & 486,217 & 0,0 & & & & & \\
\hline T3 & 950,644 & 165,155 & 0,0 & & & & \\
\hline $\mathrm{T} 4$ & 388,647 & 52,893 & 226,152 & 0,0 & & & \\
\hline $\mathrm{T} 5$ & 283,873 & 171,258 & 256,058 & 167,964 & 0,0 & & \\
\hline T6 & 512,676 & 47,334 & 72,536 & 82,679 & 8,176 & 0,0 & \\
\hline $\mathrm{T} 7$ & 593,008 & 27,594 & 75,797 & 66,652 & 152,969 & 15,984 & 0,0 \\
\hline
\end{tabular}

*T1, T2, T3, T4, T5, T6 e T7 referem-se aos genótipos procedentes de Caucaia, Paracuru, Lagoa Redonda, Sabiaguaba, Verdão, Verdão SF177 e Juazeiro do Norte, respectivamente

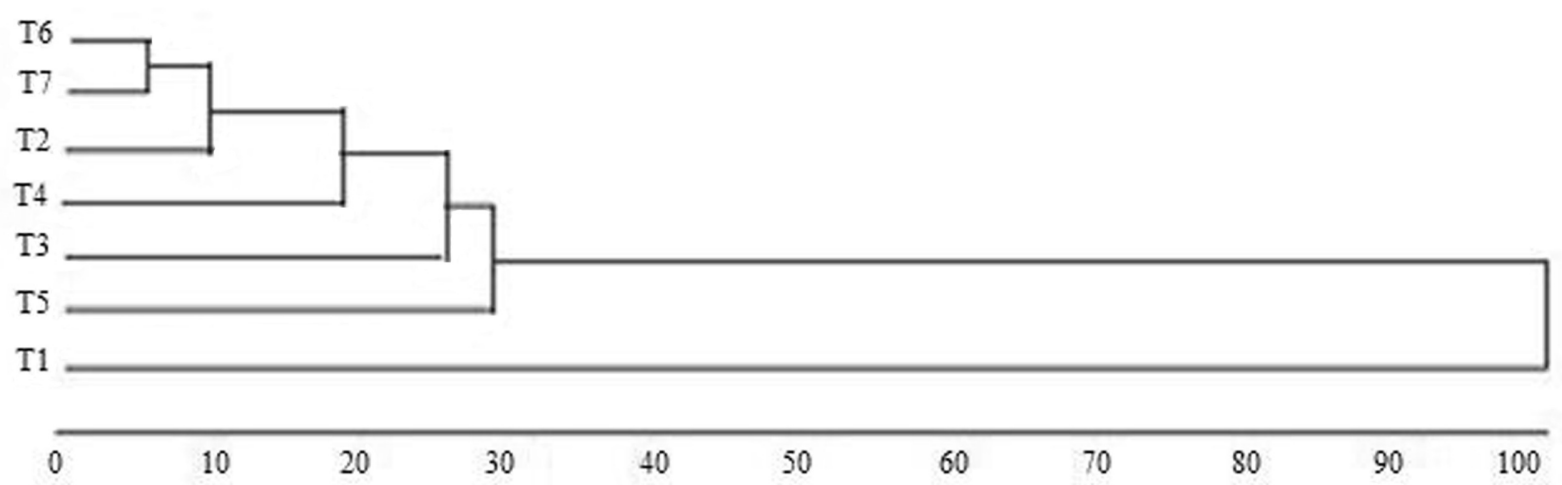

Figura 1 - Dendrograma resultante da análise de agrupamento realizado por meio do método do vizinho mais próximo obtido a partir da medida de dissimilaridade entre os 21 pares de genótipos 
A análise de componentes principais reduziu as dez características em dois componentes principais (CP1 e CP2), que explicaram $81,3 \%$ da variância total (TAB 3). Em estudos similares Barbieri et al. (2005), mostrou que os três primeiros componentes explicaram $77 \%$ da variação total em acessos de cebolas, enquanto que Rodrigues (2001) e Choer e Silva (2000) mostraram que os quatro primeiros componentes explicaram $70 \%$ e $76,6 \%$ da variação total, respectivamente, em acessos de feijão e abóbora. Cruz e Regazzi (2004) recomendam valores em torno de $80 \%$. O componente 1 (CP1), que explicou $58,0 \%$ da variância total, está associado a um contraste entre dois grupos de variáveis. Dentre as variáveis de maior peso neste componente pode-se citar: NFA, MSF, SPI, IA, IAF e TAF. O componente 2 (CP2), que explicou 23,0\% está associado aos seguintes descritores: D,UMB e A.

A representação gráfica dos dois primeiros componentes principais das dez características avaliadas está apresentada na Figura 2. De acordo com a dispersão gráfica dos genótipos, observa-se uma maior proximidade entre o genótipo 6 (cultivar Verdão SF177) e o genótipo 7 (Juazeiro), e um maior distanciamento entre os genótipos 5 (cultivar Verdão) e 1 (genótipo de Caucaia), em relação aos demais. Resultados semelhantes também foram observados por meio do agrupamento realizado utilizando-se o método do vizinho mais próximo. Portanto, pode-se considerar que, de um modo geral, os dois métodos utilizados na formação dos grupos foram coerentes.

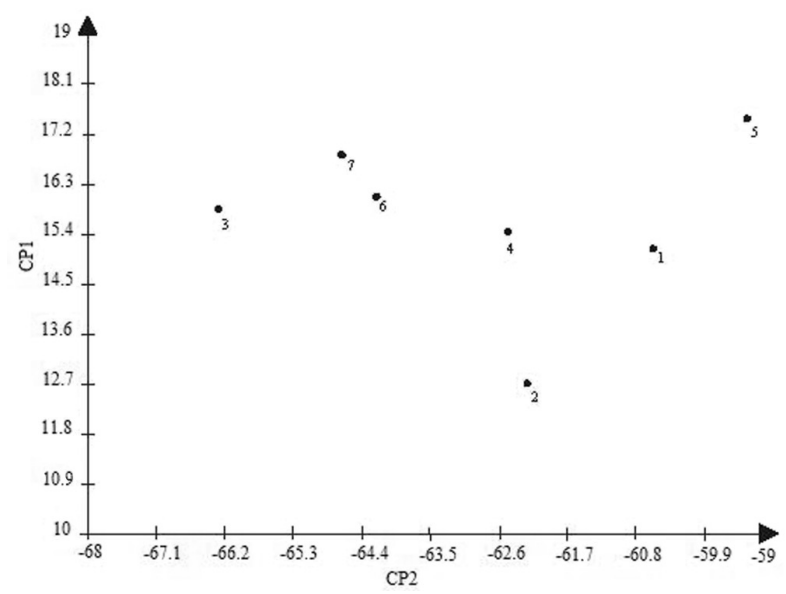

Figura 2 - Representação gráfica dos resultados da análise de Componentes Principais (CP) de sete genótipos de coentro T1, T2, T3, T4, T5, T6 e T7 procedentes de Caucaia, Paracuru, Lagoa Redonda, Sabiaguaba, Verdão, Verdão SF177 e Juazeiro do Norte, respectivamente. Baseados nos escores de dez características fenológicas e agronômicas

Tabela 3 - Estimativa das variâncias (autovalores), associados aos componentes principais (CP), e respectivos coeficientes de ponderação (autovetores) de dez características fenológicos e agronômicas avaliadas em sete genótipos de coentro

\begin{tabular}{ccccccccccc}
\hline \multirow{2}{*}{ Características** CPmponentes Principais } \\
\cline { 2 - 12 } & \multicolumn{1}{c}{ CP1 } & \multicolumn{1}{c}{ CP2 } & \multicolumn{1}{c}{ CP3 } & \multicolumn{1}{c}{ CP4 } & \multicolumn{1}{c}{ CP5 } & \multicolumn{1}{c}{ CP6 } & \multicolumn{1}{c}{ CP7 } & CP8 & \multicolumn{1}{c}{ CP9 } & CP10 \\
\hline NFA & 0,401 & $-0,042$ & 0,133 & 0,185 & 0,370 & $-0,233$ & $-0,391$ & 0,000 & $-0,642$ & 0,173 \\
MSF & $-0,395$ & $-0,036$ & 0,063 & $-0,199$ & 0,616 & $-0,266$ & $-0,357$ & $-0,408$ & 0,111 & 0,207 \\
SPI & $-0,382$ & 0,044 & $-0,171$ & 0,439 & $-0,212$ & 0,040 & 0,498 & 0,541 & $-0,038$ & 0,207 \\
IA & $-0,327$ & $-0,163$ & $-0,335$ & 0,564 & 0,266 & $-0,142$ & $-0,096$ & $-0,578$ & 0,043 & 0,011 \\
D & $-0,120$ & 0,610 & 0,021 & 0,274 & $-0,216$ & $-0,122$ & $-0,419$ & 0,125 & $-0,238$ & $-0,477$ \\
IAF & $-0,377$ & $-0,138$ & $-0,201$ & $-0,349$ & $-0,282$ & 0,263 & $-0,052$ & $-0,206$ & $-0,687$ & $-0,105$ \\
TAF & $-0,353$ & 0,266 & $-0,120$ & $-0,377$ & 0,292 & 0,077 & 0,488 & $-0,134$ & 0,202 & $-0,509$ \\
UMB & 0,220 & 0,518 & $-0,216$ & 0,081 & 0,357 & 0,601 & 0,030 & $-0,042$ & $-0,049$ & 0,037 \\
PCF & $-0,234$ & $-0,245$ & 0,667 & 0,260 & 0,130 & 0,553 & $-0,056$ & 0,004 & $-0,019$ & $-0,216$ \\
A & 0,213 & $-0,423$ & $-0,538$ & 0,048 & 0,113 & 0,311 & $-0,205$ & 0,360 & 0,012 & 0,451 \\
\hline Auto-valores & 5,80 & 2,32 & 1,09 & 0,572 & 0,16 & 0,05 & 0 & 0 & 0 & 0 \\
\hline V.A.(\%)* & 58,05 & 81,27 & 92,17 & 97,91 & 99,48 & 100,0 & 100,0 & 100,0 & 100,0 & 100,0 \\
\hline
\end{tabular}

*NFA - Número de folhas aproveitáveis; MSF- mudança do sistema foliar; SPI- surgimento da primeira inflorescência; IA- início da antese; Ddiâmetro do colo do caule; IAF- início do amadurecimento do fruto; TAF- término do amadurecimento do fruto; UMBE- umbelete/umbela; PCFpeso de cem frutos e A- altura.

*V.A.(\%) - variância acumulada, em percentagem 
A técnica de análise multivariada de componentes principais tem a vantagem em relação aos métodos de análise univariada de avaliar a importância de cada característica estudada sobre a variação total disponível entre os acessos avaliados, possibilitando o descarte dos caracteres menos discriminantes (MARTINELLO et al., 2002). Seguindo os critérios recomendados por Jolliffe $(1972,1973)$ e Mardia et al. (1979), as características menos discriminantes e passíveis de serem descartadas foram: TAF, IAF, IA, SPI, UMB e MSF (TAB 3). De acordo com Rosse e Fernandes (2002), esse critério é mais eficiente em discriminar as características menos informativas quando se considera um conjunto de no mínimo dez características.

\section{Conclusões}

Considerando um único ano agrícola e as condições do ambiente em que o estudo foi realizado, pode-se inferir os seguintes pontos conclusivos:

1. Os genótipos T1 e T7 são superiores quanto à produção de frutos e mais indicados para cultivo e utilização em programas de melhoramento;

2. A maior distância do genótipo $\mathrm{T} 1$ em relação aos demais indica que este genótipo é o mais divergente, podendo ser usado em cruzamentos com os outros genótipos para a obtenção de populações segregantes e identificação de genótipos transgressivos.

\section{Agradecimentos}

Ao MEC - SESu, especificamente ao Programa de Educação Tutorial (PET), pelo auxílio financeiro e concessão de bolsas.

\section{Referências}

BARROS JÚNIOR, A. P. et al. Desempenho agronômico de cultivares comerciais de coentro em cultivo solteiro sob condições de temperatura elevada e ampla luminosidade. Caatinga, v. 17, n. 02, p. $82-86,2004$.

BARBIERI, R. L. et al. Divergência genética entre populações de cebola com base em marcadores morfológicos. Ciência Rural, v. 35, n. 02. p. 303-308, 2005.

BENIN, G. et al. Comparações entre medidas de dissimilaridade e estatísticas multivariadas como critérios no direcionamento de hibridações em aveia. Ciência Rural, v. 33, n. 04, p. 657-662, 2003.

BERTINI, C. H. C. de M.; TEÓFILO, E. M.; DIAS, F. T. C. Divergência genética entre acessos de feijão-caupi do banco de germoplasma da UFC. Revista Ciência Agronômica, v. 40, n. 01, p. 99-105, 2009.

BEZERRA, A. M. E.; PINHEIRO, J.; CHAVES, F. C. M. Hortaliças cultivadas no cinturão verde de Fortaleza e análise bacteriológica da água utilizada. Horticultura. Brasileira, v. 08 , n. 01, p. $35,1990$.

CHOER, E.; SILVA, J. B. Avaliação de divergência genética entre acessos de Cucurbita ssp. através de análise multivariada. Agropecuária de Clima Temperado, v. 03, p. 213-219, 2000.

COSTA, J. C. et al. Caracterização molecular de genótipos de coentro (Coriandrum sativum L.) utilizando os marcadores molecular ISSR e RAPD. Disponível em: <http://www. adevento.com.br/jepex/cdrom/resumos/R0007.3.pdf $>$. Acesso em: 10 abr. 2008 .

CRUZ, C. D. Programa genes: aplicativo computacional em genética e estatística. Viçosa: UFV, 2001. 648 p.

CRUZ, C. D.; REGAZZI, A. J.; CARNEIRO, P. C. S. Modelos biométricos aplicados ao melhoramento genético. 3. ed. Viçosa: UFV, 2004. 480 p. 1 v.

FILGUEIRA, F. A. R. Novo manual de olericultura: Agrotecnologia Moderna na Produção e Comercialização de Hortaliças. 2 ed. Viçosa: UFV, 2000. 240 p.

JOLLIFFE, I. T. Discarding variables in a principal component analysis; I. Artifical data. Applied Statistics, v. 21, n. 02, p. 160-173, 1972

JOLLIFFE, I. T. Discarding variables in a principal component analysis. II: Real data. Applied Statistics, v. 21, n. 01, p. $21-31,1973$

LIMA, J. S. S. et al. Desempenho agroeconômico de coentro em função de espaçamentos e em dois cultivos. Revista Ciência Agronômica, v. 38, n. 04, p. 407-413, 2007.

MARDIA, K. V.; KENT, J. T.; BIBBY, J. M. Multivariate analysis. London: Academic Press, 1979, 521 p.

MARQUES, F. C.; LORENCETTI, B. C. Avaliação de três cultivares de coentro (Coriandrum sativum L.) semeadas em duas épocas. Pesquisa Agropecuária Gaúcha, v. 05, p. 265270, 1999.

MARTINELLO, G. E. et al. Divergência genética em acessos de quiabeiro com base em marcadores morfológicos. Horticultura Brasileira, v. 20, n. 01, p. 52-58, 2002

OLIVEIRA, A. P. et al. Desempenho de genótipos de coentro em Areia. Horticultura Brasileira, v. 25, n. 02, p. 252-255, 2007.

PEREIRA, R. S.; MUNIZ, M. F. B.; NASCIMENTO, W. M. Aspectos relacionados à qualidade de sementes de coentro. Horticultura Brasileira, v. 23, n. 03, p. 703-706, 2005.

RANGAHAU, M. K.Coriander. Crop \& Food Research [Broad sheet]. 2001. Disponível em: $<$ http://www.crop.cri.nz/ home/productsservices/publications/broadsheets/030coriander. pdf $>$. Acesso em: 10 abr. 2008.

RODRIGUES, L. S. Caracterização e divergência genética de cultivares de feijão (Phaseolus vulgaris L.). 2001. 92 f. 
Dissertação (Mestrado em Agronomia) - Universidade Federal de Pelotas, Pelotas.

ROSSE, L. N.; FERNANDES, J. S. C. Escolha de caracteres para o melhoramento genético em erva-mate por meio de técnicas multivariadas. Ciência Florestal, v. 12, n. 01, p. 21-27, 2002.

SANTOS, C. A. F.; OLIVEIRA, C. A. V.; MENEZES, E. A. Seleção de descritores na caracterização e avaliação preliminar de germoplasma de guandu. Pesquisa Agropecuária Brasileira, v.30, p.971-975, 1995.
SANTOS, R. C. et al. Classificação de genótipos de amendoim baseada nos descritores agromorfológicos e isoenzimáticos. Ciência Rural, v. 30, n. 01, p. 55-59, 2000.

SUDRÉ, C. P. et al. Divergência genética entre acessos de pimenta e pimentão utilizando técnicas multivariadas. Horticultura brasileira, v. 23, n. 01, p. 22-27, 2005.

WANDERLEY JÚNIOR, L. J. G; NASCIMENTO, W. M. Produção de sementes de coentro. 2008. Disponível em: $<$ http://www.abhorticultura.com.br $>$. Acesso em: 10 abr. 2008. 